\title{
The pupillary and ciliary components of the cat Edinger-Westphal nucleus: A transsynaptic transport investigation
}

\author{
JONATHAN T. ERICHSEN ${ }^{1}$ AND PAUL J. MAY ${ }^{2}$ \\ ${ }^{1}$ Department of Optometry and Vision Sciences, Cardiff University, Cardiff, Wales, CF10 3NB, United Kingdom \\ ${ }^{2}$ Departments of Anatomy, Ophthalmology and Neurology, University of Mississippi Medical Center, Jackson \\ (Received March 8, 2001; ACCEPTEd December 5, 2001)
}

\begin{abstract}
The distribution of preganglionic motoneurons supplying the ciliary ganglion in the cat was defined both qualitatively and quantitatively. These cells were retrogradely labeled directly, following injections of wheat germ agglutinin conjugated to horseradish peroxidase (WGA-HRP) into the ciliary ganglion, or were transsynaptically labeled following injections of WGA into the vitreous chamber. Almost half of the cells are distributed rostral to the oculomotor nucleus, both in and lateral to the anteromedian nucleus. Of the remaining preganglionic motoneurons, roughly $20 \%$ of the total are located dorsal to the oculomotor nucleus. Strikingly few of these neurons are actually found within the Edinger-Westphal nucleus proper. Instead, the majority are found in the adjacent supraoculomotor area or along the midline between the two somatic nuclei. An additional population, roughly $30 \%$ of the total, is located ventral to the oculomotor nucleus. This study also provides evidence for a functional subdivision of this preganglionic population. Pupil-related preganglionic motoneurons were transsynaptically labeled by injecting WGA into the anterior chamber, while lens-related preganglionic motoneurons were transsynaptically labeled by injecting WGA into the ciliary muscle. The results suggest that the pupil-related preganglionic motoneurons, that is, those controlling the iris sphincter pupillae muscle, are located rostrally, in and lateral to the anteromedian nucleus. In contrast, lens-related preganglionic motoneurons, that is, those controlling the ciliary muscle are particularly prevalent caudally, both dorsal and ventral to the oculomotor nucleus. Thus, the cat intraocular muscle preganglionic innervation is spatially organized with respect to function, despite the dispersed nature of its distribution.
\end{abstract}

Keywords: Oculomotor, Lens, Iris, Parasympathetic, Accommodation, Near response

\section{Introduction}

As in all vertebrates, the intraocular muscles of the cat are innervated by the postganglionic parasympathetic cells of the ciliary ganglion. This ganglion mediates both the pupillary light reflex and visual accommodation through its control of the iris and ciliary muscle, respectively. Classically, the preganglionic parasympathetic motoneurons that supply the ciliary ganglion are said to be located in the Edinger-Westphal nucleus, based on studies in macaques (Warwick, 1954; Pierson \& Carpenter, 1974; Gamlin et al., 1994). Presumably homologous structures containing ciliary preganglionics have been identified as the nucleus of EdingerWestphal in a variety of nonmammalian vertebrate species (Reiner et al., 1983; Somiya et al., 1992; Henning \& Himstedt, 1994). However, the location of the preganglionic cells in nonprimate mammalian species has been more difficult to specify. In the cat, most of the preganglionic motoneurons are actually located outside the confines of the Edinger-Westphal nucleus, whereas the major-

Address correspondence and reprint requests to: Paul J. May, Department of Anatomy, University of Mississippi Medical Center, 2500 North State Street, Jackson, MS 39216-4505, USA. E-mail: pjm@ anat.umsmed.edu ity of the cells within this nucleus project centrally (Sugimoto et al., 1977, 1978; Loewy et al., 1978; Toyoshima et al., 1980; Maciewicz et al., 1983, 1984). Descriptions of the extent and precise location of the preganglionic motoneuron distribution have varied between studies.

As indicated above, the parasympathetic pathway to the eye subserves two functions. Consequently, the extent to which the preganglionic motoneurons may be organized into functionspecific groups or subdivisions of pupillary and lens-related preganglionic cells has been investigated with electrophysiological techniques. Specifically, in the cat, pupillary constriction was produced by electrical stimulation at a variety of midbrain sites, but particularly rostral and ventral to the oculomotor nucleus (Ranson \& Magoun, 1933; Hare et al., 1935; Sillito \& Zbrozyna, 1970a). Extracellular recordings in cat localized pupilloconstrictor activity to the region of the oculomotor midline, as well as in the pretectum and points in between (Sillito \& Zbrozyna, 1970b; Hultborn et al., 1978).

Accommodation-related preganglionic cells have been mapped dorsal and lateral to the oculomotor nucleus in the cat (Bando et al., 1984). There is also evidence for a spatial dichotomy between pupil and lens areas from stimulation experiments in 
monkeys (Jampel \& Mindel, 1967; Clarke et al., 1985b; Crawford et al., 1989). At present, there is little corresponding anatomical evidence for functional localization in the mammalian EdingerWestphal nucleus. This is due to the fact that the two neuron autonomic circuit involving the postganglionic cells of the ciliary ganglion precludes the normal approach taken with extraocular muscles, in which a muscle-specific motoneuron population may be directly retrogradely labeled.

Functional subdivisions related to control of the iris, ciliary muscle, and choroid circulation have been demonstrated anatomically in the avian Edinger-Westphal nucleus (Reiner et al.,1983; Gamlin \& Reiner, 1991). Erichsen and Evinger (1985) have utilized retrograde transsynaptic transport of wheat germ agglutinin in order to label preganglionic motoneurons in these different avian subdivisions following injections of specific postganglionic targets. The present study seeks to utilize this same methodology in the cat to (1) precisely define the locations of the entire preganglionic population and quantify the relative distribution of motoneurons in each location, and (2) to specify the distributions of preganglionic motoneurons related to either pupillary constriction or lens accommodation. Preliminary reports of this investigation have appeared in abstract form (Erichsen et al., 1992). The identification of function-specific preganglionic motoneuron pools will facilitate anatomical determination of premotor inputs related to pupil and to lens control, either as components of the pupillary light reflex or the near response.

\section{Methods}

\section{Injection protocols}

Four different injection protocols were utilized in this study. Injections were made into the ciliary ganglion, the vitreous chamber, the anterior chamber, or the ciliary muscle. A total of 21 adult cats were used. All these procedures were done in accordance with $\mathrm{NIH}$ regulations and with the approval of the institutional animal care and use committee.

\section{Ciliary ganglion injections}

Through the use of a direct retrograde tracer method, the baseline distribution of preganglionic parasympathetic motoneurons projecting in the third nerve was determined by injecting the ciliary ganglion. Injections of the ciliary ganglion were carried out utilizing an aseptic technique in a sterile surgery suite. Animals were anesthetized with sodium pentobarbital (35 mg/kg, IP), placed in a stereotaxic apparatus, and maintained at a surgical level of anesthesia utilizing supplementary (IV) doses. Dexamethasone ( $2 \mathrm{mg} / \mathrm{kg}$, IM) was given to control edema. The orbit was approached dorsally, following unilateral aspiration of a small portion of the frontal pole of cortex and removal of the overlying bony sinus. By use of a 10- $\mu 1$ Hamilton syringe, the ciliary ganglion was injected with 2-8 $\mu$ l of a solution containing $1.0 \%$ wheat germ agglutinin conjugated to horseradish peroxidase (WGA-HRP) and $10.0 \%$ horseradish peroxidase (HRP). Alternatively, HRP-coated insect pins were inserted into the ganglion until the tracer dissolved. The area was washed with saline to limit extraganglionic spread of the tracer.

These animals received butorphanol tartrate $(0.5 \mathrm{mg} / \mathrm{kg} / 6 \mathrm{~h}$, IM) over the first $24 \mathrm{~h}$, postrecovery, to alleviate any postsurgical discomfort. They survived for $24-48 \mathrm{~h}$ and showed no noteworthy postsurgical symptoms. They were then given an overdose of sodium pentobarbital $(70 \mathrm{mg} / \mathrm{kg}$, IP). Transcardiac perfusion with a buffered saline rinse was followed by perfusion with 2.01 of fixative solution containing $1.0 \%$ paraformaldehyde and $1.25 \%$ glutaraldehyde in $0.1 \mathrm{M}, \mathrm{pH} 7.2$ phosphate buffer (PB). The brain was blocked in the frontal stereotaxic plane and removed for a 1-h postfixation in the same fixative.

\section{Vitreous chamber injections}

The vitreous chamber was injected in order to produce labeling of parasympathetic preganglionic motoneurons by means of transsynaptic transport through the ciliary ganglion. Injections of the vitreal chamber were carried out using aseptic techniques. Animals were anesthetized with ketamine $\mathrm{HCl}(22 \mathrm{mg} / \mathrm{kg}$, IM). Proparacaine $\mathrm{HCl}(0.5 \%)$ drops were administered to the eye to anesthetize the cornea and conjunctiva. When no blink was elicited, 50-100 $\mu \mathrm{l}$ of $1.0 \%$ WGA (E. Y. Labs, San Mateo, CA) were injected into the vitreous using a 27 -gauge needle that was advanced through the lateral conjunctiva. The eye was then treated with gentamicin ophthalmic drops to preclude infection. As the results will show, tracer readily moved into the aqueous compartment, and so labeled irideal preganglionic neurons, and it also moved into the ciliary muscle to label ciliary preganglionic motoneurons.

These animals survived for 4 days before sacrifice, in order to allow sufficient time for transsynaptic transport of the WGA. They received butorphanol tartrate $(0.5 \mathrm{mg} / \mathrm{kg} / 6 \mathrm{~h}, \mathrm{IM})$ over the first $24 \mathrm{~h}$, postrecovery, to alleviate any discomfort. At the end of the survival period, the animals were given an overdose of sodium pentobarbital $(70 \mathrm{mg} / \mathrm{kg}$, IP). Transcardiac perfusion with a buffered saline rinse was followed by perfusion with 2.01 of fixative solution containing $4.0 \%$ paraformaldehyde in $0.1 \mathrm{M}, \mathrm{pH} 7.2 \mathrm{~PB}$. The brains were blocked in the frontal stereotaxic plane and removed, as were the ciliary ganglia. They were postfixed for 4-12 h.

\section{Anterior chamber injections}

The anterior chamber was injected in order to preferentially label, by transsynaptic transport, the preganglionic parasympathetic motoneurons that control the iris sphincter pupillae muscle. The injection procedure was the same as used for the vitreous chamber injections with the following exceptions. When no blink reflex was elicited, 20-40 $\mu$ l of aqueous were removed from the anterior chamber to avoid an increase in intraocular pressure. The needle was then reinserted and 15-25 $\mu$ l of $1.0 \%$ wheat germ agglutinin (WGA) were injected into the anterior chamber. The 27-gauge injection needle was passed through the cornea at an oblique angle to facilitate closure of the defect. After injection, the head position was manipulated to insure that the tracer spread evenly through the anterior chamber. Survival and procedures for fixation were the same as for vitreal chamber injections.

\section{Ciliary muscle injections}

The ciliary muscle was directly injected in order to preferentially label, via transsynaptic transport, the preganglionic motoneurons that control lens curvature. In this case, the animals were anesthetized with sodium pentobarbital (35 mg/ $\mathrm{kg}$, IP) and placed in a stereotaxic apparatus. Surgery was performed in a sterile suite under aseptic conditions. The outer layer of the conjunctiva was cut and retracted to avoid tissue swelling. A specially constructed 27 -gauge needle was used to make $8.0-\mu$ injections of $1.0 \%$ WGA at 10-12 sites posterior to the cornea/sclera junction. The injection sites were evenly spread across three quadrants of the globe. The ventromedial quadrant was not injected because an appropriately 
oblique needle angle could not be obtained. The needle was cut to a very short length so that when it was fully inserted into the sclera, the tip lay in the ciliary body. This fact had been previously verified using a perfused eye. Following injection, the conjunctival surface was reapproximated and gentamicin drops were administered. The survival and perfusion procedures were the same as for the vitreous cases.

\section{Control injections}

In addition, two control experiments were performed. In the first, the corneal surface was washed with $25 \mu \mathrm{l}$ of the WGA solution to test whether labeling was due to escape of tracer through the needle defect. In the second, the anterior chamber was injected with the $15-30 \mu \mathrm{l}$ of either $10.0 \%$ HRP or $1.0 \%$ Fluorogold, in order to test whether the labeling seen in the central nervous system was produced by direct, as opposed to transsynaptic, transport.

\section{Histological protocols}

The brains from the ciliary ganglion injection cases were cut into 50 - or $100-\mu \mathrm{m}$ sections on a vibratome. A one-in-three series of sections was reacted to reveal the presence of the HRP using a modification of the technique of Olucha et al. (1985) (May \& Porter, 1998). Briefly, the sections were rinsed in $0.1 \mathrm{M}, \mathrm{pH}$ 6.0 PB and then preincubated in a solution containing $0.25 \%$ ammonium molybdate and $0.005 \%$ tetramethylbenzidine in $0.1 \mathrm{M}, \mathrm{pH} 6.0 \mathrm{~PB}$ for $20 \mathrm{~min}$. The reaction was initiated with $0.009 \%$ hydrogen peroxide, and the sections incubated overnight at $4^{\circ} \mathrm{C}$. The sections were rinsed again and mounted onto gelatinized slides. They were then conterstained with cresyl violet, dehydrated, cleared, and coverslipped. Each of the sections was charted independently using a drawing tube attached to a photomicroscope.

The brains from the cases used in the three transsynaptic protocols all underwent the same histological procedures. They were equilibrated in a $30 \%$ buffered sucrose solution as a cryoprotectant. They were then frozen and cut into $35-\mu \mathrm{m}$ sections using a sliding microtome. A one-in-three series was reacted with antibody to WGA utilizing an adaption of the ABC technique (Collins et al., 1991). Briefly, the sections were treated in $0.3 \% \mathrm{H}_{2} \mathrm{O}_{2}$ for $10 \mathrm{~min}$ to remove endogenous peroxidase activity. They were rinsed $0.1 \mathrm{M}, \mathrm{pH} 7.2 \mathrm{~PB}$ and placed in $1.5 \%$ normal goat serum for $30 \mathrm{~min}$. Following another PB rinse, they were incubated for $12 \mathrm{~h}$ at $4^{\circ} \mathrm{C}$ in rabbit anti-WGA (E.Y. Labs) [1:250 or $1: 500$ in $0.1 \mathrm{M}, \mathrm{pH} 7.2 \mathrm{~PB}$ with $0.3 \%$ Triton-X100] that had been preabsorbed through a 2-h incubation with cerebellum sections. After being rinsed in $\mathrm{PB}$, the sections incubated in biotinylated ant-rabbit $\operatorname{IgG}[1: 10$ in $0.1 \mathrm{M}, \mathrm{pH} 7.2 \mathrm{~PB}$ with $0.3 \%$ Triton-X100] for $1 \mathrm{~h}$. A standard ABC kit reaction using diaminobenzidene was then used. An adjoining series was stained with cresyl violet. The transsynaptically labeled cells were charted using phase optics on a photomicroscope equipped with a drawing tube.

The ganglia from selected cases were also equilibrated in $30 \%$ buffered sucrose, embedded in OCT compound, and cut at $15 \mu \mathrm{m}$ on a cryostat. Sections of ganglia were reacted using the anti-WGA protocol described above. One in every three sections through the ganglia were drawn, and the labeled and unlabeled cells were charted using phase optics on a photomicroscope equipped with a drawing tube.
Analysis

Due to the dispersed nature of the cat preganglionic motoneurons, we utilized quantitative means to (1) establish the actual distribution of these neurons in the ciliary ganglion injection cases, and (2) show whether the transsynaptic experiments produced statistically significant distribution differences indicative of functional compartmentalization. In all cases, counts were made of labeled central nervous system cells in a one-in-three series of sections. By use of phase contrast optics, the borders of the surrounding nuclei could be determined and the numbers of labeled cells within each area defined. Only cells in which the entire somatic profile was clearly visible were included in the analysis. Nuclear borders were confirmed by comparison to the adjoining cresyl violet stained section. These counts and those of the ganglion cells were multiplied by a factor of 3 without correction. In the ciliary ganglion, where the use of phase optics made the nucleoli clearly visible, only cells in which the nucleolus was present were counted. This degree of resolution was not possible in the brain-stem sections because neither nucleoli nor cell nuclei were consistently apparent. Means, standard errors (SE), and standard deviations (SD) of the population were determined. Comparisons were made using a $t$-test, assuming unequal variance, in which $P$ values of less than 0.05 were considered significant, and less than 0.02 were highly significant.

\section{Results}

\section{Ciliary ganglion injections}

Following an injection of the ciliary ganglion, retrogradely labeled cells were distributed throughout an extensive area of the midbrain tegmentum, as shown in Fig. 1. All the labeled cells were located on the side ipsilateral to the injection. Rostral to the oculomotor nucleus, retrogradely labeled preganglionic cells (dots) were present in the anteromedian nucleus, as well as lateral to it (A-C). At the level of the oculomotor nucleus (D-J), some retrogradely labeled cells were present in the Edinger-Westphal nucleus (D-G), but the majority were found lateral to it in the supraoculomotor area (D) and along the midline (D-G). Somatic motoneurons (diamonds) were also labeled (D-J), presumably due to spread of tracer to the extraocular muscles and/or the oculomotor nerve. Labeled preganglionic motoneurons were present ventral to the oculomotor nucleus (D-G) and somatic motoneurons were sometimes present in and lateral to the medial longitudinal fasciculus (I-J). Presumptive differentiation between the somatic motoneurons and those preganglionic motoneurons located along the midline was based primarily on cell size. Ventral to the medial longitudinal fasciculus, cells lateral to the exiting oculomotor nerve bundles were assumed to be somatic motoneurons.

A quantitative breakdown of the distribution of cells labeled following a ciliary ganglion injection is shown in the Fig. 2 histogram and Table 1 . In the ten cases with ciliary ganglion injections, a mean total of $718(\mathrm{SE}=89)$ preganglionic cells were observed. Of these, $48.2 \%$ ( $\mathrm{SE}=3.2 \%$ ) of the total labeled preganglionic population were located rostral to the oculomotor nucleus (III). These rostral cells were divided between those cells located within the anteromedian nucleus (about 1/3) and those lateral to it (the remaining $2 / 3$ ). Of the total population labeled following a ganglion injection, $19.3 \%(\mathrm{SE}=1.9 \%)$ of the total were located dorsal to the oculomotor nuclei. This population could be subdivided between those within the Edinger-Westphal 

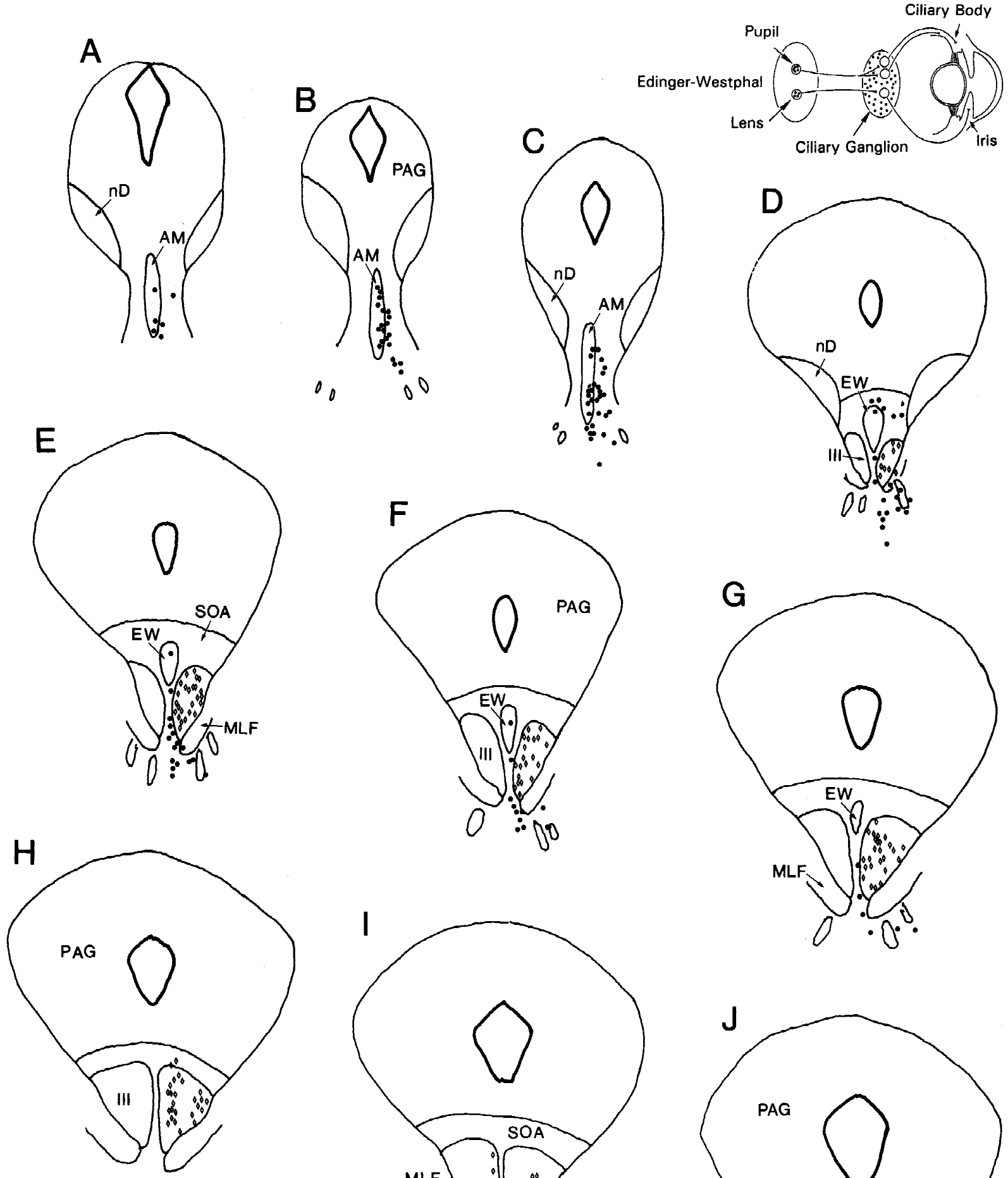


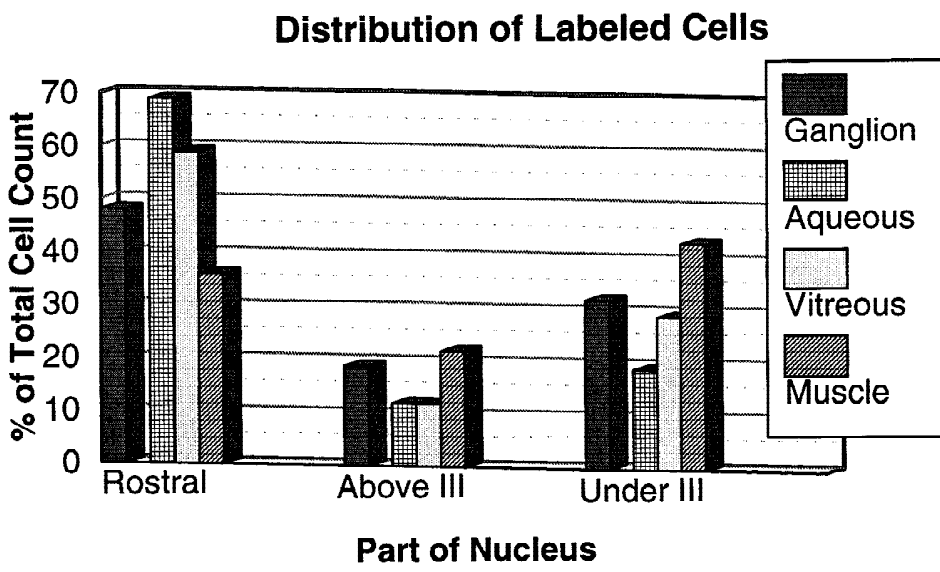

Fig. 2. Bar graph showing the relative frequency of preganglionic motoneuron labeling in the three regions of interest [Rostral: in and lateral to the anteromedian nucleus; Above III: in the EdingerWestphal nucleus, supraoculomotor area, or between the oculomotor nuclei; Under III: ventral to the oculomotor nucleus] after injections of tracer were placed in the ciliary ganglion $(n=10)$, the aqueous of the anterior chamber $(n=5)$, the vitreal chamber $(n=2)$, or the ciliary muscle $(n=2)$. Compare the direct labeling pattern seen after the ganglion injection to the three transsynaptic patterns. nucleus (approximately $1 / 4$ of the dorsal cells), lateral to it within the supraoculomotor area (approximately $1 / 2$ the dorsal cells), and on the midline between the oculomotor nuclei (about $1 / 4$ of the dorsal cells). The final group of cells was found ventral to the oculomotor nucleus and medial longitudinal fasciculus. These represented $32.2 \%$ ( $\mathrm{SE}=3.1 \%$ ) of the total preganglionic population. As indicated by the standard errors, there was relative uniformity in the distribution of the preganglionic motoneurons across animals, considering that the effectiveness of the ganglionic injections varied dramatically (range: 273-1392 cells).

\section{Vitreous chamber injections}

The distribution of preganglionic motoneurons observed in the ganglion injection cases was confirmed following injections into the vitreous chamber, as illustrated in Fig. 3. Labeled cells were observed rostral to the oculomotor nucleus (A-C), in and lateral to the anteromedian nucleus. In addition, they were present dorsal to the oculomotor nucleus (D-J), both within the Edinger-Westphal nucleus and in the surrounding supraoculomotor area, as well as along the midline. Finally, labeled cells were found ventral to the oculomotor nucleus (D-H). In this case, very limited somatic labeling was observed. It was restricted to the caudal pole of the oculomotor nucleus, in a distribution suggestive of the inferior oblique's motoneuron pool ( $\mathrm{J})$.

The average number of preganglionic cells labeled in these cases $(n=2)$ was $405(\mathrm{SE}=30)$, more than half $(56 \%)$ of that seen following ganglion injections. This extent of transsynaptic labeling was not obviously correlated with the amount of direct retrograde labeling of postganglionic neurons in the ipsilateral ciliary ganglion. Out of a mean total of 1670 nucleolated ganglion cells,
$32.6 \%$ of the total were labeled $(n=2)$. The majority of the transsynaptically labeled cells $(59.0 \%$ of the total) were found rostral to the oculomotor nucleus, both in and lateral to the anteromedian nucleus (Fig. 2 and Table 1). Of the remaining labeled cells, $11.5 \%$ were located dorsal to the oculomotor nucleus and $29.0 \%$ were located ventral to the oculomotor nucleus. The proportion of cells found rostrally in these cases was significantly greater than observed after ganglion injections $(P=0.003)$. In light of the fact that the distribution of transsynaptically labeled cells was not significantly different from that of the anterior injection cases (see below), it seems that a significant amount of tracer entered the iris and was picked up by pupillary afferents. However, the large number of labeled cells indicates that there was significant uptake by lens afferents as well. Thus, these cases provide a picture of the overall preganglionic cell distribution, as demonstrated by a technique different from those previously employed. Cell labeling along the midline and beneath the oculomotor nucleus in these cases strengthens the interpretation that cells at these locations are preganglionic, as opposed to somatic, motoneurons.

\section{Anterior chamber injections}

Since all labeling was located ipsilateral to the ganglion injected (see above), both eyes were sometimes used in the transsynaptic cases. For example, the distribution of the transsynaptically labeled preganglionic motoneurons observed following bilateral injections of the anterior chambers is illustrated in Fig. 4. Most of the labeled cells were located rostral to the oculomotor nucleus (A-C), both in and lateral to the anteromedian nucleus. Only a few cells were observed either dorsal to the oculomotor nucleus (E \& G), or

Table 1. Regional frequency of preganglionic labeling

\begin{tabular}{|c|c|c|c|c|c|c|c|c|c|c|}
\hline \multirow[b]{2}{*}{ Target } & \multirow[b]{2}{*}{$N$} & \multicolumn{3}{|c|}{ Rostral to III } & \multicolumn{3}{|c|}{ Above III } & \multicolumn{3}{|c|}{ Under III } \\
\hline & & Mean $\%$ & $\mathrm{SD}$ & $\mathrm{SE}$ & Mean $\%$ & SD & $\mathrm{SE}$ & Mean \% & $\mathrm{SD}$ & $\mathrm{SE}$ \\
\hline Ganglion & 10 & 48.2 & 10.2 & 3.2 & 19.3 & 5.9 & 1.9 & 32.2 & 9.7 & 3.1 \\
\hline Aqueous & 5 & 69.0 & 13.8 & 6.9 & 11.8 & 5.7 & 2.9 & 19.0 & 11.5 & 5.8 \\
\hline Vitreous & 2 & 59.0 & 0.0 & 0.0 & 11.5 & 3.5 & 3.5 & 29.0 & 4.0 & 4.0 \\
\hline Muscle & 2 & 35.5 & 15.5 & 15.5 & 22.0 & 15.0 & 15.0 & 42.5 & 0.5 & 0.5 \\
\hline
\end{tabular}


A

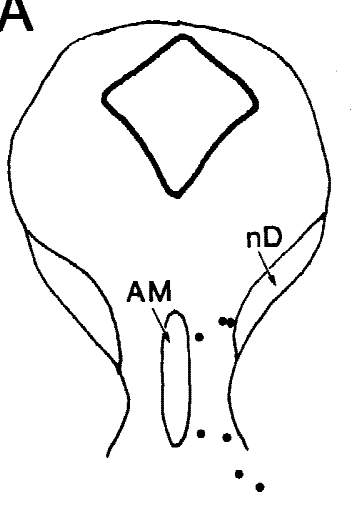

$\mathrm{B}$

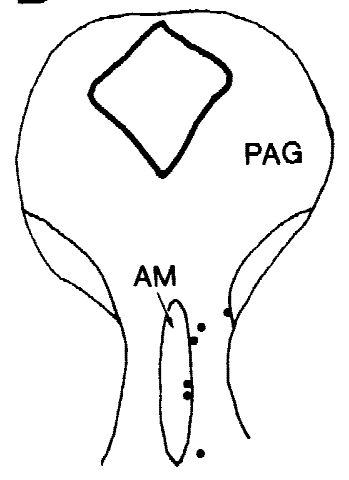

Ciliary Body

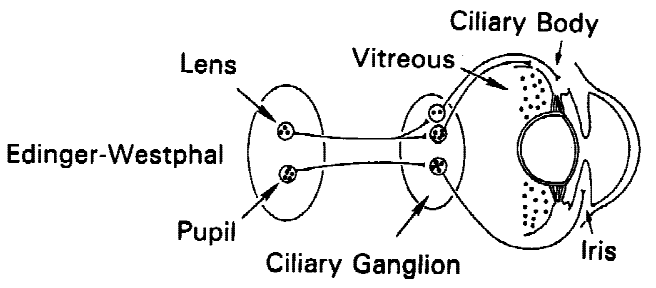

C

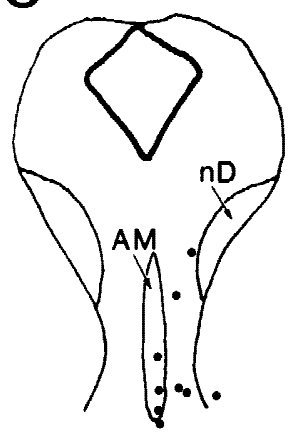

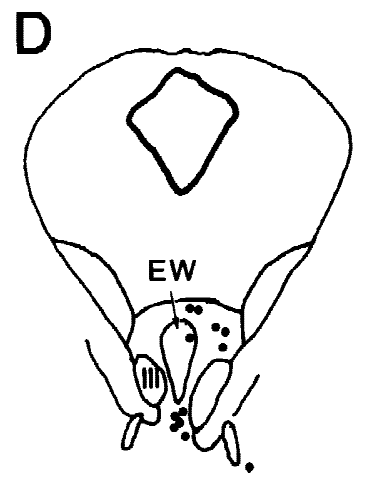

$\mathrm{E}$
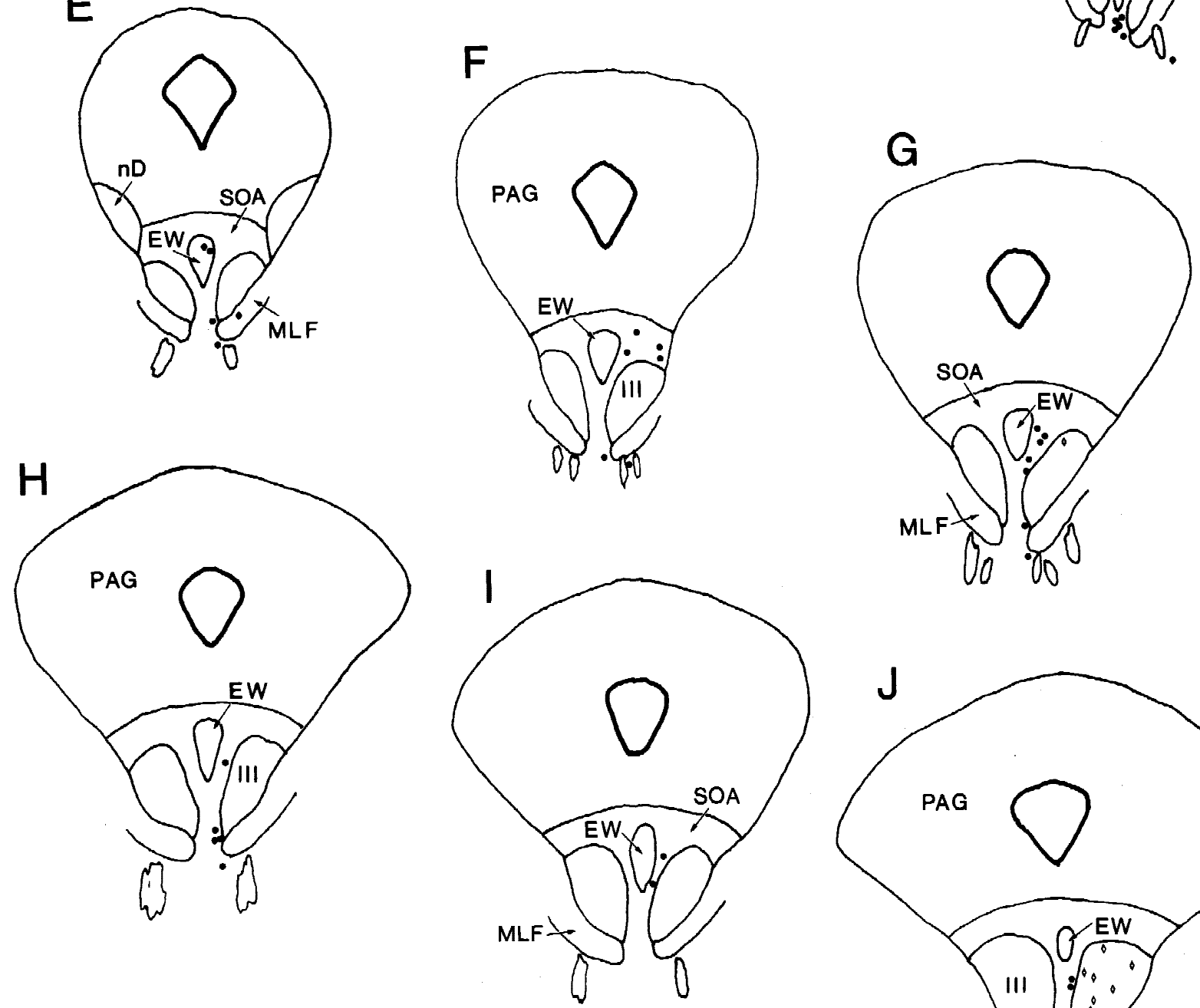

$1.0 \mathrm{~mm}$

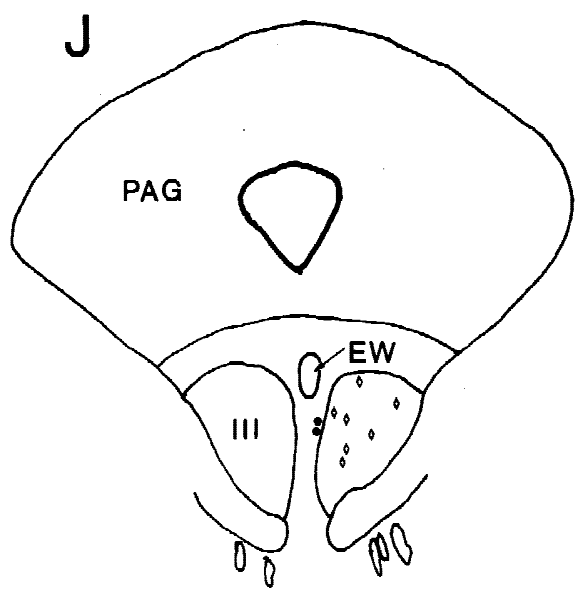

Fig. 3. Charting of the labeling pattern following injections of tracer (upper right insert) into the vitreous of the right eye. Transsynaptically labeled preganglionic motoneurons (dots) are present rostral, dorsal, and ventral to the oculomotor nucleus. In addition, a few labeled somatic motoneurons (diamonds) are present in the oculomotor nucleus caudally. 


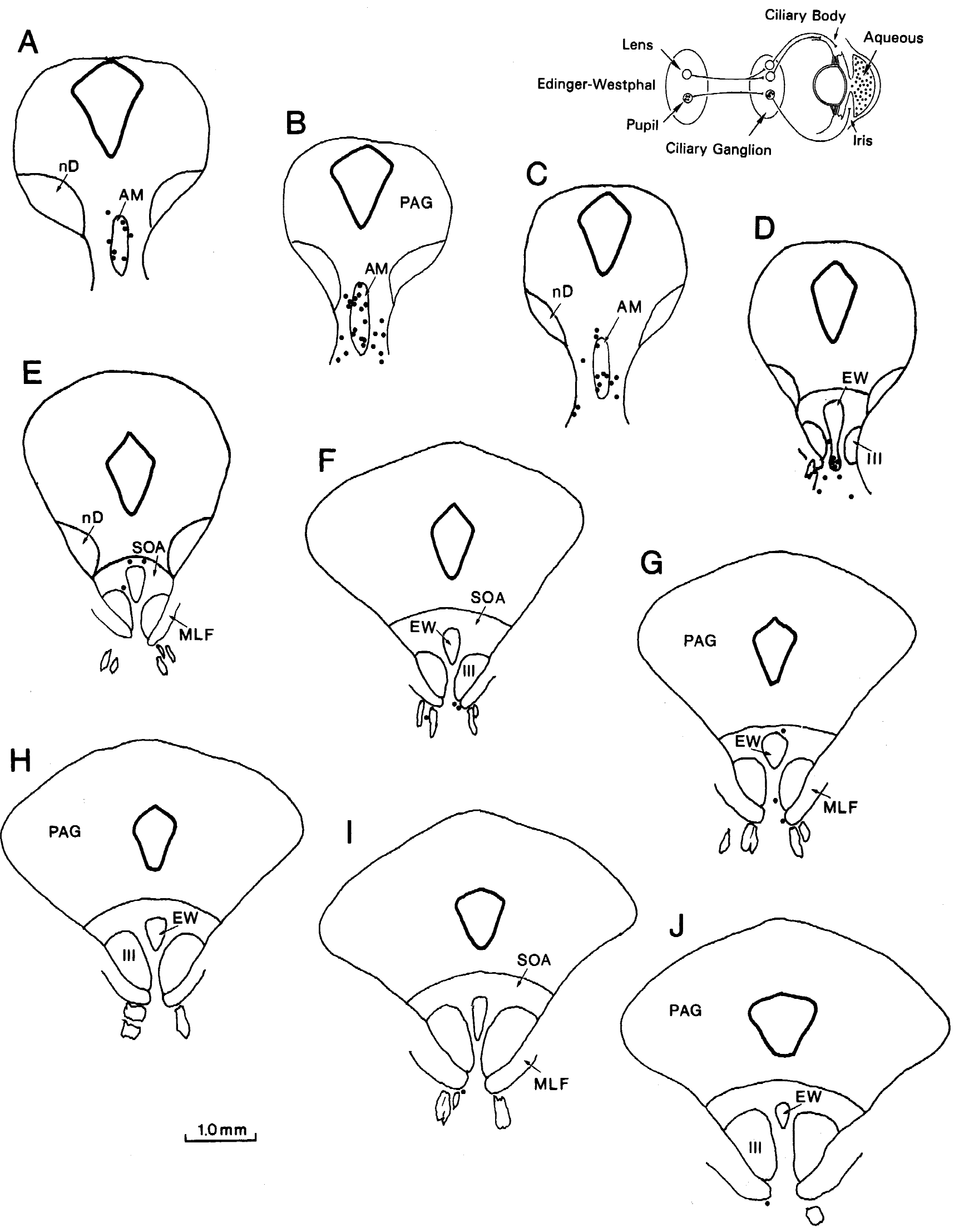

Fig. 4. Charting of the labeling pattern following injections of tracer (upper right insert) into both anterior chambers. Transsynaptically labeled preganglionic motoneurons (dots) are present rostral, dorsal, and ventral to the oculomotor nucleus. However, most cells were present rostrally, in and lateral to the anteromedian nucleus. 
ventral to it (D-G). Most small injections (less than $20 \mu \mathrm{l}$ ) of the anterior chamber did not produce any labeled somatic motoneurons. In the case of the anterior chamber injections, the physical appearance of transsynaptically labeled brain-stem cells under phase-contrast optics is shown in Fig. 5. The crystalline nature of the reaction product was readily observed in the transsynaptically labeled neurons (Figs. 5B \& 5C) because it had a bright blue appearance under phase-contrast optics, in contrast to the other elements which were shades of gray. The borders of the antero- median nucleus, and the labeled cells scattered in and lateral to it, are also visible under phase-contrast conditions (Fig. 5A).

The mean number of preganglionic cells labeled in the anterior chamber cases $(n=5)$ was $281(\mathrm{SE}=26)$, just $39 \%$ of the mean observed following ganglion injections. As shown in Fig. 2 and Table 1, following the anterior chamber injection, $69.0 \%$ ( $\mathrm{SE}=$ $6.9 \%$ ) of the transsynaptically labeled cells were located rostral to the oculomotor nucleus, both in and around the anteromedian nucleus. Only $11.8 \%(\mathrm{SE}=2.9 \%)$ of the total were located dorsal

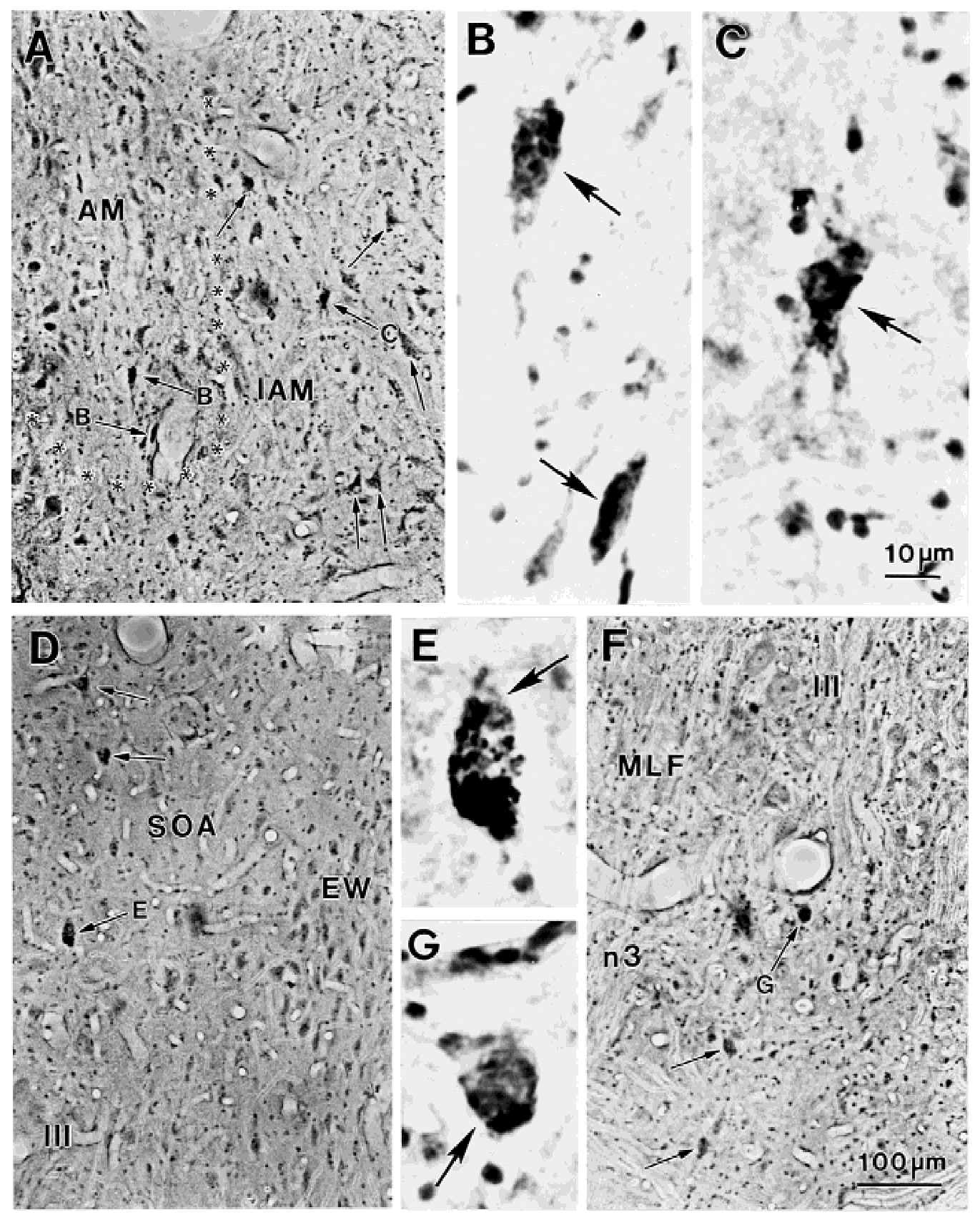

Fig. 5. Phase-contrast photomicrographs of transsynaptically labeled (large arrows) preganglionic motoneurons following injection of tracer into the anterior chamber $(A-C)$ or ciliary muscle $(D-G)$. Labeled cells in and lateral to the border (asterisks) of the anteromedian nucleus (A) are shown at higher magnification in B \& C. The reaction product appeared as bright blue particles. A labeled cell in the supraoculomotor area (D) is shown at higher magnification in E. Similarly, a labeled cell beneath the oculomotor nucleus (F) is shown at higher magnification in G. Scale bar in F = A,D; and C = B,E, \& G. 
to the oculomotor nuclei. Just $19.0 \%(\mathrm{SE}=5.8 \%)$ of the total were found ventral to the oculomotor nucleus. A $t$-test comparison between the distribution of label following aqueous injections and injections of the ciliary ganglion showed a highly significant $(P=$ 0.017 ) difference between the two, with a far greater percentage of cells present rostral to the oculomotor nucleus in the anterior chamber injection cases. The difference between the values for the areas dorsal and ventral to the oculomotor nucleus also reached significance $(P=0.030$ and 0.045 , respectively).

In Fig. 6, both conventional (A) and phase-contrast (B) images show the presence of reaction product in scattered ganglion cells following anterior chamber injections. A similar labeling pattern was present following vitreal and ciliary muscle injections. The level of labeling varied from cell to cell. In the most heavily labeled cells, crystalline reaction product filled the cytoplasm, and a ring of perinuclear crystals emphasized the border of the cell nucleus. Labeled puncta were also present, adjacent to both labeled and unlabeled cells. In the ipsilateral ciliary ganglion, a mean total of 1017 clearly nucleolated cells were counted $(n=2)$. Of these, $31.7 \%$ contained some direct retrograde label and $12.2 \%$ of the total were heavily stained following anterior chamber injections.

\section{Ciliary muscle injections}

The distribution of the preganglionic motoneurons transsynaptically labeled following injections of the ciliary muscle is illustrated in Fig. 7. Only a few labeled cells were observed rostral to the oculomotor nucleus $(\mathrm{A}-\mathrm{C})$, either in or lateral to the anteromedian nucleus. Instead, the majority of cells were located either dorsal to the oculomotor nucleus (D-I), in the Edinger-Westphal nucleus and the supraoculomotor area, or ventral to it (D-I). Retrograde somatic labeling in the oculomotor nucleus was absent in one case and limited to its caudal pole $(\mathrm{J})$ in the other. Anterogradely labeled terminals in the visual sensory nuclei, indicating tracer spread from the ciliary muscle to the retina, were present in both cases. Examples of the labeled cells can be seen in Fig. 5 (D-G). In both cases, most cells were observed caudally. In one case, more cells were evident dorsal to the oculomotor nucleus, in the Edinger-Westphal nucleus and in the supraoculomotor area (Figs. 5D \& 5E). In the other case, more of the cells were present ventral to the oculomotor nucleus, medial to and amongst the exiting third nerve fibers (Figs. 5F \& 5G).

In these cases $(n=2)$, the quantitative breakdown of the distribution of the transsynaptically labeled preganglionic cells reveals that of a mean total of 446 cells, only $35.5 \%$ of the total were distributed rostral to the oculomotor nucleus (Fig. 2 and Table 1). On the other hand, $22.0 \%$ of the total were distributed dorsal to the oculomotor nucleus, and $42.5 \%$ of the total were distributed ventral to the oculomotor nucleus. The percentage of cells found below the oculomotor nucleus was higher following ciliary muscle injections than following injections of either the ganglion, or the aqueous, and these differences were highly significant $(P=0.004$ and 0.008 , respectively). Within the ciliary ganglion $(n=2)$, a mean total of 2407 nucleolated cells were counted. Of these, $32.1 \%$ were retrogradely labeled.

\section{Control injections}

No labeling whatsoever was observed in the ciliary ganglion or the brain stem following application of WGA onto the cornea. Injection of the anterior chamber with either fluorogold or HRP produced retrograde labeling in the ciliary ganglion. The former never
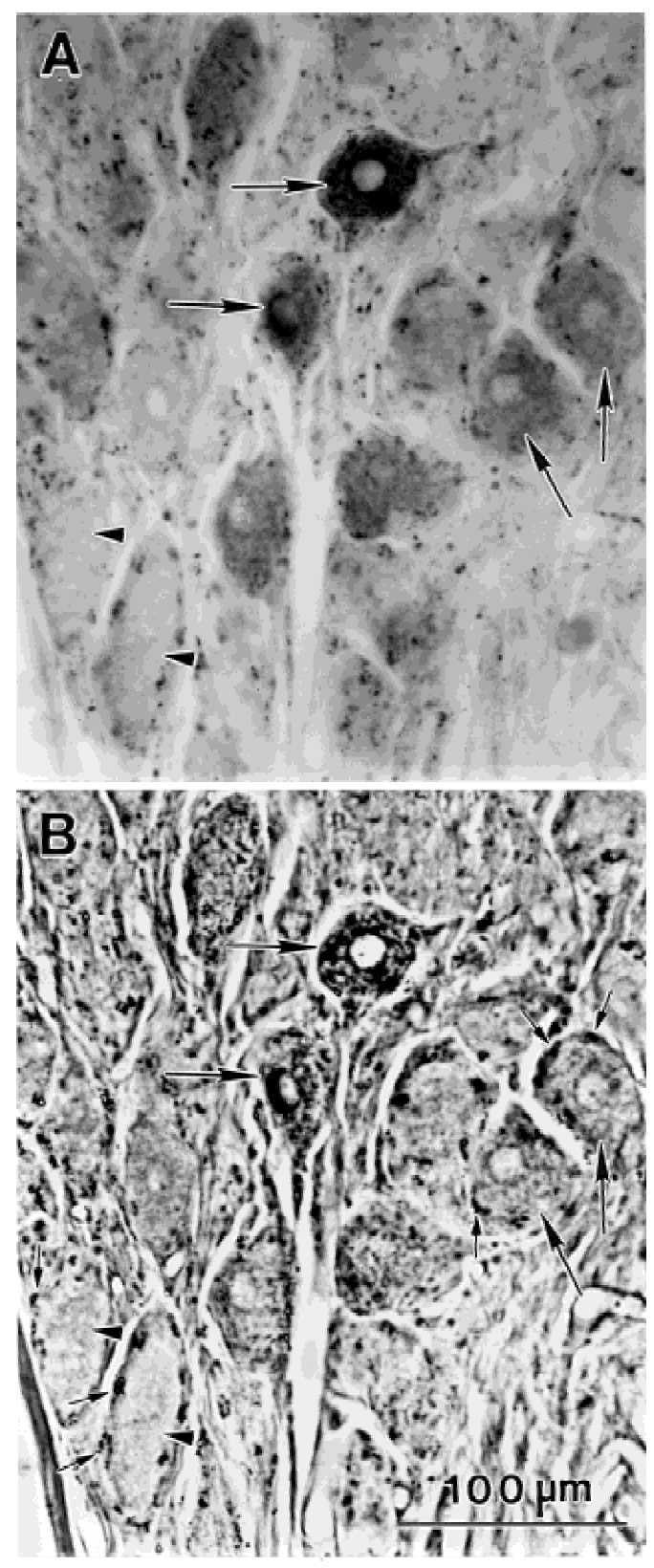

Fig. 6. Bright-field (A) and phase-contrast (B) photomicrographs of postganglionic motoneurons in the ciliary ganglion following injection of the anterior chamber. The degree of tracer present in the labeled cells (large arrows) varied. Labeled puncta (small arrows) were also present in the neuropil surrounding both the labeled and unlabeled cells (arrowheads). Scale in $\mathrm{A}=\mathrm{B}$.

produced labeling centrally. With very large injections of HRP into the anterior chamber, a few labeled cells were sometimes present on the midline, between the oculomotor nuclei. However, the character of this labeling was much denser than transsynaptic labeling, and it always occurred in conjunction with scattered labeling of somatic subdivision cells, indicating leakage of tracer along the extraocular muscle insertions. It seems likely that these cells are small somatic motoneurons that project to the multiply innervated muscle fibers that extend into the muscle insertion (Büttner-Ennever et al., 2001), although Kuchiiwa and colleagues 
A

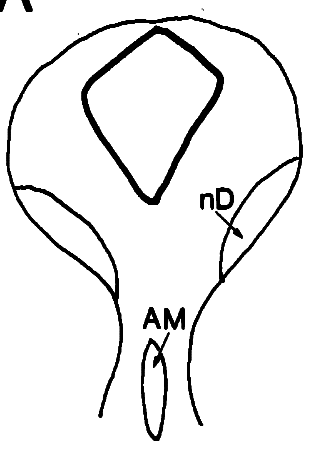

$\mathrm{E}$

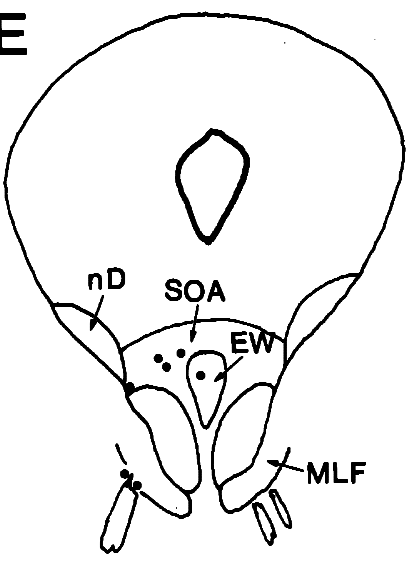

$\mathrm{B}$

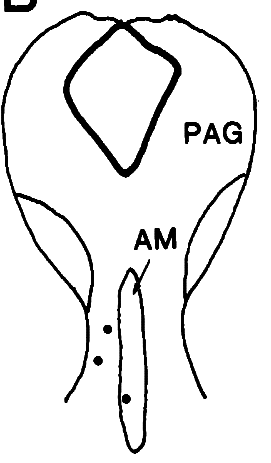

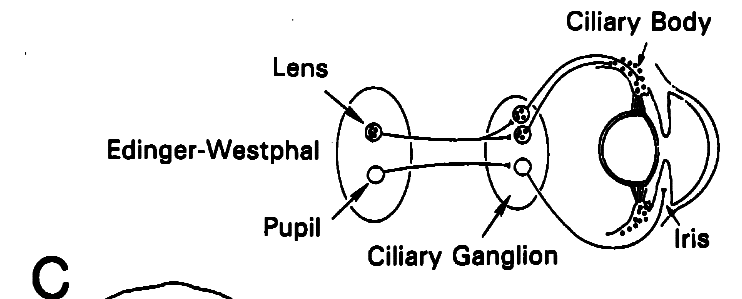
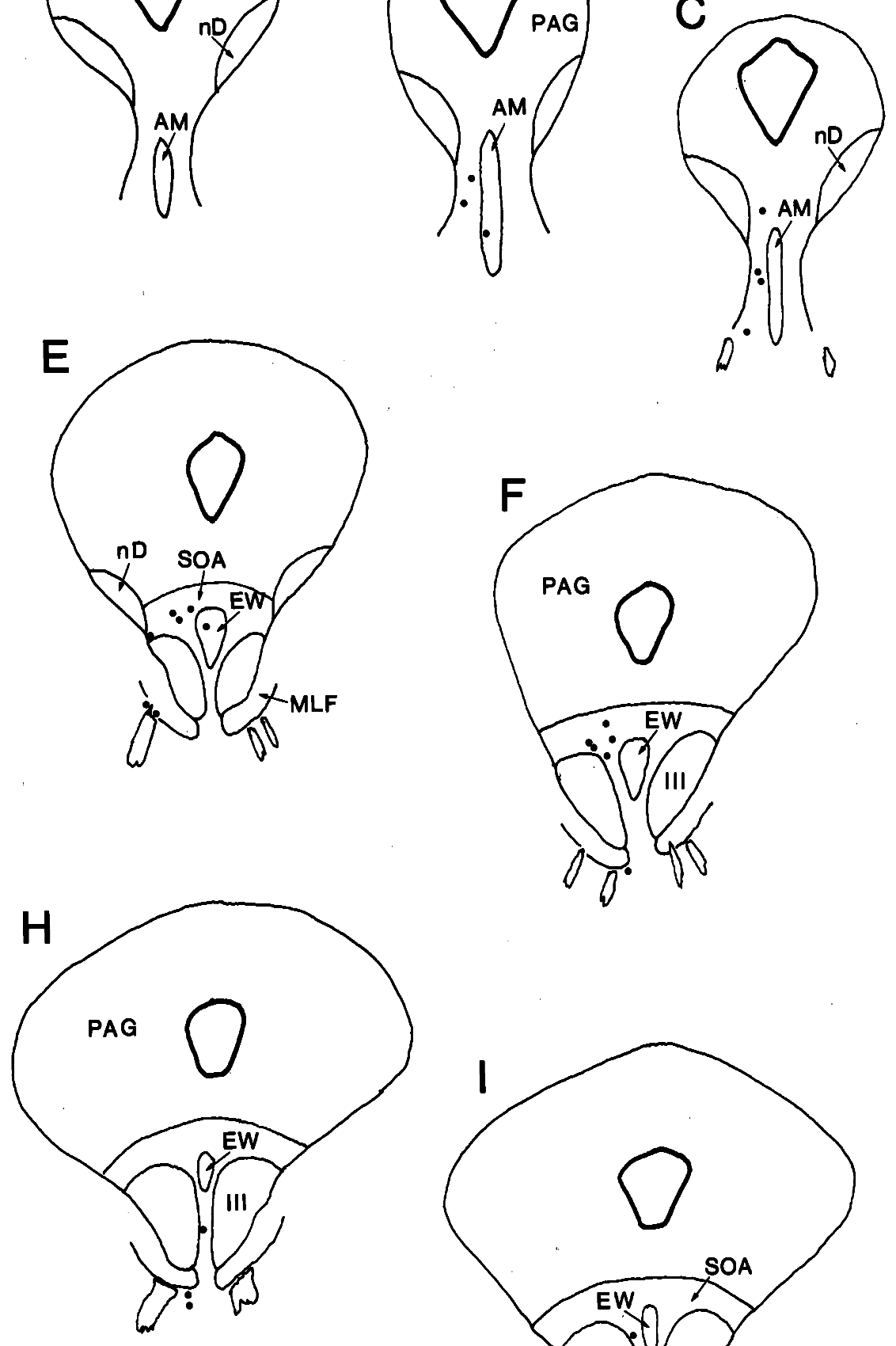

$1.0 \mathrm{~mm}$
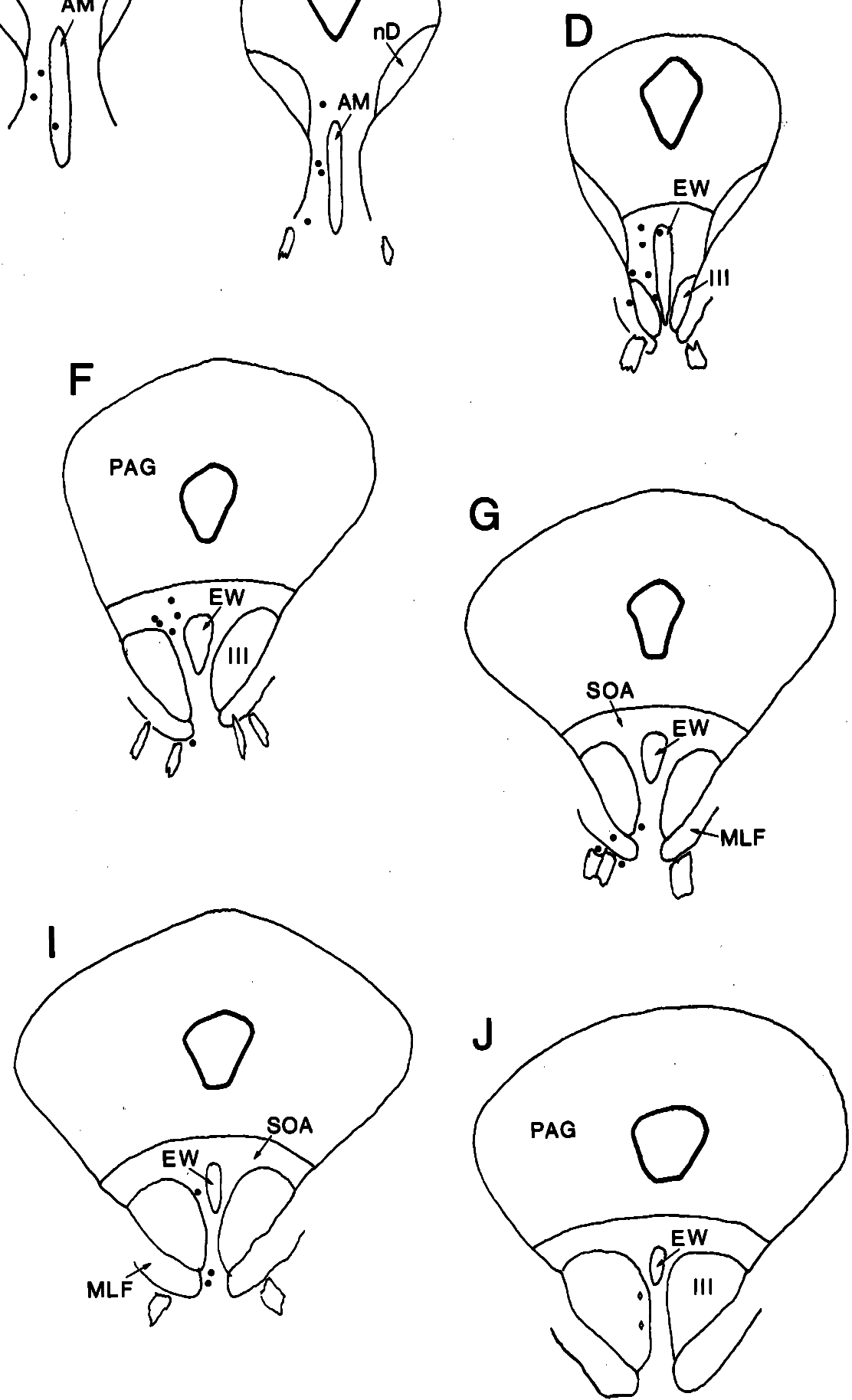

Fig. 7. Charting of the labeling pattern following injections of tracer (upper right insert) into the ciliary muscle of the left eye. Transsynaptically labeled preganglionic motoneurons (dots) are mainly found caudally, dorsal, and ventral to the oculomotor nucleus. In addition, labeled somatic motoneurons (diamonds) are present in the oculomotor nucleus caudally. 
(1994) have argued that they represent preganglionic motoneurons that supply episcleral postganglionic motoneurons.

\section{Discussion}

The results of these experiments indicate, for the first time, an anatomical division within the preganglionic motoneuron population of a mammal with respect to the functions of pupillary constriction and lens accommodation. This finding was made possible by comparison of the aqueous and ciliary muscle cases to a quantitative analysis of the general population, which showed that the distribution of preganglionic motoneurons is quite consistent. Thus, the results of this study provide a necessary basis for further investigation of pupil and lens control circuits.

\section{Technical considerations and implications}

As in any experiments involving the use of retrograde transport, spread of the injected tracer away from the intended target complicates interpretation of the observed cell labeling. In the present experiments, this difficulty must be examined with respect to both ciliary ganglion injections and injections of the globe. In addition, the ability to define target-specific preganglionic neurons depends on the specificity of the transsynaptic transport in the ganglion. However, examination of ganglia with the light (present data) and electron microscope (personal observation) showed no evidence that tracer is generally present in the extracellular space. Furthermore, the extensive glial wrappings in the ganglia would preclude nonsynaptic transport (May \& Warren, 1993).

Following WGA-HRP injections of the ciliary ganglion, the presence of labeled cells in the somatic subdivision of the oculomotor nucleus indicates spread of the tracer to adjacent nerve and muscle. Smaller injections largely precluded somatic labeling, but they also labeled far fewer of the preganglionic neurons, limiting their usefulness in providing the baseline data needed for this study. Tracer spread makes it somewhat difficult to discriminate unambiguously between somatic and preganglionic motoneurons, because the former are sometimes found outside the boundaries of the oculomotor nucleus (Evinger, 1988). In these cases, we based the distinction on the relative size and location of the labeled cells. The subsequent transsynaptic experiments with vitreous chamber injections supported this distinction. They selectively labeled the smaller neurons located ventromedial to the oculomotor nucleus, but produced little or no labeling within the boundaries of the nucleus. Thus, there is clear evidence that some preganglionic motoneurons are located ventral to the oculomotor nucleus in the cat. Similarly, these data indicate that there are preganglionic neurons along the midline between the two somatic nuclei, but do not exclude the presence of smaller somatic motoneurons in this same region (Büttner-Ennever et al., 2001).

In the present study, injections of the anterior chamber were used to label the postganglionic and preganglionic afferents to the iris sphincter pupillae muscle. Not only is the route of the outflow through the trabecular meshwork in close proximity to the ciliary muscle, a portion of the aqueous outflow passes through the ciliary body (Inomata et al., 1972; Millar et al., 1998). In monkey, this path represents a substantial outflow route (Bill, 1966b), but probably only $3 \%$ of the aqueous outflow takes this route in cat (Bill, 1966a). Therefore, the potential for spread to the ciliary muscle is correspondingly reduced. Nevertheless, it was clearly not possible to label the pupillary cells to the exclusion of ciliary cells.
It was, however, possible to produce a considerable enrichment in the labeling of the pupillary preganglionic population relative to the ciliary one. Bearing in mind the fact that lesion experiments suggest that the pupillary population is quite small (Warwick, 1954), this point is supported graphically by Fig. 8A. Anterior chamber injections, that labeled fewer cells overall, actually produced a higher percentage of labeled cells rostral to the oculomotor nucleus. If these injections had not preferentially labeled pupillary preganglionic motoneurons, or if the pupillary neurons were distributed randomly in the brain stem, then the relationship would graph as a horizontal line at a fixed percentage, instead of the nearly linear increase observed as the total number of labeled cells
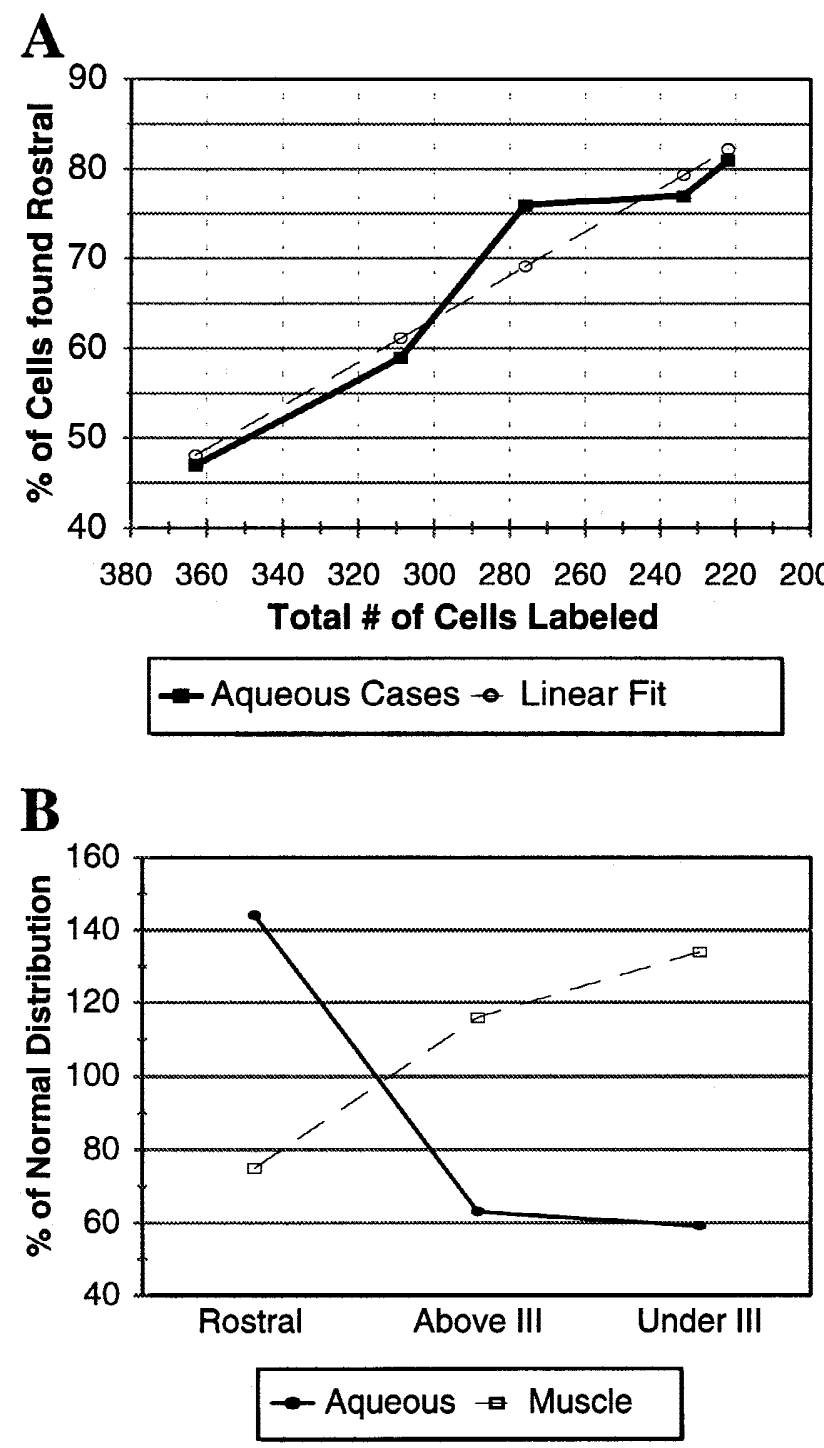

Fig. 8. A: Graph of cases which had anterior chamber injections showing the relationship (bold line) between the total number of labeled cells and the percent of those labeled cells found in and lateral to the anteromedian nucleus. The relationship is close to a linear fit (dashed line) with a line described by $y=0.22 x+5.57$. B: Graph comparing the distribution pattern of aqueous injection cases (solid line) to ciliary muscle injection cases (dashed line). The percent of labeling in each region is expressed with respect to a normative value $(100 \%)$ represented by the mean distribution following injections of the ciliary ganglion. 
decreased (Fig. 8A). Based on this evidence, we propose that the pupillary subdivision is located in and around the anteromedian nucleus, rostral to the oculomotor nucleus. These data suggest that a few pupillary preganglionics are scattered more caudally. However, in light of the potential for tracer spread, these data are also consistent with the pupillary function being entirely confined to the anteromedian nucleus and its immediate surround.

It is similarly apparent that spread to the iris may have occurred following injections of the ciliary muscle. The extracellular space of the ciliary muscle and iris are not divided into separate compartments (Freddo et al., 1990). However, in view of the aqueous outflow direction, and the narrowness of the region of continuity between the iris and the ciliary body, it seems likely that diffusion of tracer into the iris and anterior chamber would be quite limited (Freddo et al., 1990; Kardon \& Weingeist, 1998). On the other hand, the path of the pupillary postganglionic axons past the ciliary muscle provides an opportunity for fiber of passage uptake. As the results make clear, direct injections of the ciliary muscle labeled a subpopulation of preganglionic cells whose rostrocaudal distribution is roughly a mirror image of that obtained after injections into the anterior chamber. This distributional difference is specifically illustrated in Fig. 8B, where the results from the aqueous and muscle injections are plotted in terms of the normal values provided by the ganglion injections. Although the number of cases with ciliary muscle injections is small, in light of the highly significant differences between the distributions found after anterior chamber and ciliary muscle injections, it seems reasonable to conclude that most accommodative preganglionic motoneurons are located dorsal and ventral to the oculomotor nucleus. A portion of the rostral population is probably lens related as well, but our analysis could not differentiate the functional populations within this region.

A direct projection to the intrinsic eye muscles from the central nervous system has been reported in the rabbit and the monkey (Jaeger \& Benevento, 1980; Parelman et al., 1984), and such a direct pathway was proposed to explain electrophysiological data gathered in the monkey (Westheimer \& Blair, 1973). More recently, the existence of such a pathway has been effectively refuted in the monkey (Ruskell \& Griffiths, 1979; Burde, 1988b). Any direct connections between preganglionic motoneurons and the intrinsic eye muscles of the cat would complicate the interpretation of the present results. However, this does not appear to be the case, based on the results of the control experiments. These results agree with those of similar cat experiments done by Kuchiiwa et al. (1994). These authors suggested that there are a small number of midline cells which innervate episcleral ganglia (Givner, 1939). If present, these may have been directly labeled by our injections. However, since the midline population represents less than $5 \%$ of the total labeled population, the present results must be largely due to transsynaptic transport of WGA via the ciliary ganglion and accessory ganglia (Kuchiiwa et al., 1989).

\section{Labeling in the ciliary ganglion}

Within the ciliary ganglion, both cell bodies and puncta were labeled following injections of the anterior and vitreal chambers, as well as the ciliary body. No target specific distribution was observed within the ganglion, suggesting that the cells controlling the lens and pupil are intermixed. Furthermore, there was no obvious difference in the somatic diameters of the two populations. The anterior chamber injections that produced differential distributions of central labeling generally resulted in approximately
$20 \%$ labeling in the ganglion. Previous estimates of the postganglionic innervation have suggested that only $3 \%$ of the cells in the ciliary ganglion supply the iris of the macaque (Warwick, 1954). However, we feel that even assuming that a portion of the ganglionic labelling was due to spread of tracer into the ciliary muscle, it is likely that $10-15 \%$ of the postganglionic population subserves the pupil. The $3 \%$ figure was obtained by studying chromatolysis after iridectomy, and it is likely that such a peripheral axon cut in the face of numerous other reinnervation targets in the anterior segment would result in only a part of the postganglionic population undergoing chromatolysis. Furthermore, in the rabbit ganglion, where the postganglionic population is almost entirely composed of pupillary fibers, there are 380 neurons (Johnson \& Purves, 1981). The iris of the cat and rabbit are roughly comparable in size. Assuming they have similar levels of innervation, these 380 cells would represent approximately $13.8 \%$ of the average of 2836 ganglion cells $(n=6, \mathrm{SE}=243)$ that we observed in the cat. Note that this overall cell count is roughly similar to that reported for cat by Warwick (1954).

The presence of labeled puncta in the ciliary ganglion is not surprising, in light of the transsynaptic movement of WGA in the system. However, the association of some labeled puncta with cells that were not labeled was unexpected. There are several possible explanations for this phenomenon. These puncta may represent terminals of axon collaterals belonging to transsynaptically labeled local circuit neurons within the ganglia. However, in view of the small number of these cells (Warwick, 1954; Johnson \& Purves, 1983; May \& Warren, 1993; Sun et al., 1994), it seems unlikely that they could produce such a robust phenomenon. It is also possible that axon collaterals of preganglionic motoneurons are being labeled (Collins et al., 1991). Thus, the labeling of puncta around unlabeled ciliary neurons may be evidence for preganglionic divergence. Alternatively, some of these puncta may represent the labeled dendrites of ganglion cells that extend into the perisomatic neuropil of other ganglion cells (Purves, 1983).

\section{Distribution of labeled preganglionic motoneurons}

The direct retrograde labeling of preganglionic motoneurons by ciliary ganglion injections, in conjunction with their transsynaptic labeling following vitreal chamber injections, serves to demonstrate the general distribution of these parasympathetic neurons. Specifically, they are found in and lateral to the anteromedian nucleus, and they extend caudally, both dorsal and ventral to the oculomotor nucleus. The quantitative description of this distribution demonstrated that, despite an apparently diffuse organization, the location of preganglionic motoneurons in the cat is highly stereotypic. This quantitative finding provides a necessary baseline for the later experiments.

The overall distribution we observed is qualitatively comparable to that seen in previous studies in the cat (Sugimoto et al., 1977; Loewy et al., 1978), but does not display the extent shown by Toyoshima and colleagues (1980), who also illustrated preganglionic cells distributed dorsally, up to the cerebral aqueduct, and ventrally, to nearly the level of the interpeduncular nucleus. The distribution in cat (present study) is similar to that of the mouse (Vann \& Atherton, 1991), and that observed in the rabbit, although it lacks a population dorsal to the oculomotor nucleus (Johnson \& Purves, 1981). In contrast, the distribution in primates is primarily constrained to the Edinger-Westphal nucleus. In the macaque and marmoset, the majority of preganglionic motoneurons are found in the paired Edinger-Westphal nuclei located dorsal to the oculo- 
motor nucleus (Akert et al., 1980, Burde \& Loewy, 1980; Sekiya et al., 1984; Clarke et al., 1985a). This cell column is sometimes described as extending rostrally into the anteromedian nucleus (Akert et al., 1980; May et al., 1992). The lesser galago, a prosimian primate, also has the majority of its preganglionic cells located in the Edinger-Westphal nucleus, although in this species the cell column extends rostroventrally into the anteromedian nucleus and then curves caudally beneath the oculomotor nucleus (Sun \& May, 1993).

Based on the evidence described above, the areas termed the mammalian Edinger-Westphal nuclei in the primate and nonprimate should not be considered homologous structures. In fact, the present study demonstrates that only $5 \%$ of the cat preganglionic motoneurons are found in the Edinger-Westphal nucleus, proper. In cat, this nucleus and the anteromedian nucleus are primarily made up of small peptidergic neurons with central projections related to visceral autonomic responses (Burde et al., 1982; Maciewicz et al., 1983, 1984; Innis \& Aghajanian, 1986; Røste \& Dietrichs, 1988). In contrast, the nucleus termed the Edinger-Westphal in primates is primarily composed of medium-sized preganglionic motoneurons, and smaller interneurons are generally located laterally within the supraoculomotor area and in the anteromedian nucleus (Sekiya et al., 1984; Burde, 1988a; May et al., 1992; Erichsen et al., 1995). The aggregation of primate preganglionic motoneurons within a discrete nucleus may be a consequence of the greater use of precise focus and the near response in primates (Sun \& May, 1993).

\section{Functional segregation within the preganglionic population}

The present results suggest that the preganglionic motoneurons controlling the lens and pupil may be spatially organized with respect to function. Specifically, the cells controlling the pupillary sphincter are located rostrally, primarily in or near the anteromedian nucleus (Fig. 8). In contrast, those cells located caudally, dorsal and ventral to the oculomotor nucleus, control the ciliary muscle. This represents, to the best of our knowledge, the first anatomical approach to this question in mammals. In the bird, there is good evidence for functional segregation within the EdingerWestphal nucleus, based on connectional, immunohistochemical, and physiological studies (Reiner et al., 1983; Gamlin et al., 1984; Gamlin \& Reiner, 1991; Reiner et al., 1991; Fujii, 1992). However, the bird pupillary neurons are located caudolaterally, and the ciliary neurons are located ventromedially, within the lateral subdivision of the nucleus, while choroidal neurons are found in the medial subdivision.

This functional subdivision in the cat preganglionic distribution should have connectional and physiological consequences. For example, considering its role in the pupillary light reflex, the olivary pretectal nucleus in the cat should target the anteromedian nucleus. The olivary nucleus is retrogradely labeled following injections that include the anteromedian and Edinger-Westphal nuclei (Distler \& Hoffmann, 1989; Sun, 1995). There is limited anterograde evidence, however. Degenerating terminals have been reported in the rostral portion of the cat Edinger-Westphal nucleus following pretectal lesions (Itoh, 1977) and olivary pretectal nucleus injections in the rat labeled terminals rostrally (Klooster et al., 1995). Stimulation experiments in cats have produced pupilloconstriction ventral and ventrorostral to the oculomotor nucleus (Hare et al., 1935; Sillito \& Zbrozyna, 1970a). However, these effects may be due, in part, to activation of fibers of passage or activation of near-response cells that produce both lens accom- modation and pupilloconstriction. Recording experiments seem to indicate that preganglionic neurons producing lens accommodation are found dorsal to the oculomotor nucleus, in and around the Edinger-Westphal nucleus (Bando et al., 1984), while pupil-related units are primarily located near the rostral end of the oculomotor nucleus (Sillito \& Zbrozyna, 1970b). Thus, the more specific, recording experiments support the conclusions of the present study, except that the cells ventral to the oculomotor nucleus have not been investigated. The implications, if any, of the present cat findings with respect to the functional segregation of preganglionic motoneurons in primates are not clear, in light of the aforementioned differences in primate preganglionic distribution.

The presence of a functional subdivision of the cat preganglionic motoneurons, in which the control of the pupil is located rostrally and the control of the lens is located caudally, may be logical within the context of the organization of the cat midbrain. There is evidence that the anteromedian and Edinger-Westphal nuclei act as an autonomic center, with widespread brain-stem and spinal cord projections, as well as nociceptive responses (Maciewicz et al., 1983, 1984; Innis \& Aghajanian, 1986; Røste \& Dietrichs, 1988). The association of the pupillary preganglionic motoneurons with the anterior portion of this complex may allow the luminance-related activity of these neurons to be modulated with respect to the general state of the autonomic system. This possibility is supported by the fact that hypothalamic stimulation produces a profound inhibition of preganglionic pupilloconstrictor cells (Sillito \& Zbrozyna, 1970b). In contrast, the position of the lens-related preganglionic motoneurons puts them in a better position to take advantage of input related to the near response. The midbrain near-response region, which contains the premotor neurons active in controlling the lens, is believed to be located, at least in part, within the supraoculomotor area (Mays \& Porter, 1984; Judge \& Cumming, 1986; Mays et al., 1986; May et al., 1987, 1992). In the present study, roughly one-quarter of the lens-related preganglionic motoneurons were found within the supraoculomotor area. Another 50\% were found beneath the oculomotor nucleus, adjacent to the medial rectus subdivision (see Evinger, 1988). Thus, the ventrally located preganglionic motoneurons are well positioned to share inputs with their partners in the near response, the medial rectus motoneurons. In conclusion, these results provide evidence for a functional subdivision between the pupillary and accommodation related preganglionic motoneurons. This subdivision is reasonable within the limits of our present knowledge, and it provides a framework for further investigation of function-specific inputs.

\section{Acknowledgments}

These studies were supported in part by NEI Grants \#EY04587 to Jonathan T. Erichsen and \#EY07166 to Paul J. May. A portion of the ciliary ganglion cases were produced by Dr. Wensi Sun, as part of work he did toward his $\mathrm{Ph} . \mathrm{D}$. We would like to thank Angela Levine, Kim McKay, and Mindy Danielson for their expert technical assistance. We are also grateful to Drs. Craig Evinger and Susan Warren for their support from the inception of this project, and thoughtful comments on earlier drafts of this manuscript.

\section{References}

Akert, K., Glicksman, M.A., Lang, W., Grob, P. \& Huber, A. (1980). The Edinger-Westphal nucleus in the monkey. A retrograde tracer study. Brain Research 184, 491-498.

Bando, T., Tsukuda, K., Yamamoto, N., Maeda, J. \& Tsukahara, N. (1984). Physiological identification of midbrain neurons related to lens accommodation in cats. Journal of Neurophysiology 52, 870-878. 
Bill, A. (1966a). Formation and drainage of aqueous humour in cats. Experimental Eye Research 5, 185-190.

BILl, A. (1966b). Conventional and uveo-scleral drainage of aqueous humour in the cynomologous monkey (Macaca iris) at normal and high intraocular pressures. Experimental Eye Research 5, 45-54.

Burde, R.M. (1988a). Disparate visceral neuronal pools subserve spinal cord and ciliary ganglion in the monkey: A double labeling approach. Brain Research 440, 177-180.

Burde, R.M. (1988b). Direct parasympathetic pathway to the eye: Revisited. Brain Research 463, 158-162.

Burde, R.M. \& LoEwy, A.D. (1980). Central origin of oculomotor parasympathetic neurons in the monkey. Brain Research 198, 434-439.

Burde, R.M., Parelman, J.J. \& Luskin, M. (1982). Lack of unity of Edinger-Westphal nucleus projections to the ciliary ganglion and spinal cord: A double-labeling approach. Brain Research 249, 379-382.

Büttner-Ennever, J.A., Horn, A.K.E., Scherberger, H. \& D'Ascanio, P. (2001). Motoneurons of twitch and nontwitch extraocular muscle fibers in the abducens, trochlear, and oculomotor nuclei of monkeys. Journal of Comparative Neurology 438, 318-335.

Clarke, R.J., Coimbra, C.J.P. \& Alessio, M.L. (1985a). Oculomotor areas involved in the parasympathetic control of accommodation and pupil size in the marmoset (Callithrix jacchus). Brazilian Journal of Medical Biological Research 18, 373-379.

Clarke, R.J., Coimbra, C.J.P. \& Alessio, M.L. (1985b). Distribution of parasympathetic motoneurons in the oculomotor complex innervating the ciliary ganglion in the marmoset (Callithrix jacchus). Acta Anatomica 121, 53-58.

Collins, W.F., Erichsen, J.T. \& Rose, R.D. (1991). Pudendal motor and premotor neurons in the male rat: A WGA transneuronal study. Journal of Comparative Neurology 308, 28-41.

Crawford, K., Terasawa, E. \& Kaufman, P.L. (1989). Reproducible stimulation of ciliary muscle contraction in cynomologous monkey via a permanent indwelling midbrain electrode. Brain Research 503, 265-272.

Distler, C. \& Hoffmann, K-P. (1989). The pupillary light reflex in normal and microstrabismic cats, II: Retinal and cortical input to the nucleus praetectus olivaris. Visual Neuroscience 3, 139-153.

Erichsen, J.T. \& Evinger, C. (1985). Transsynaptic retrograde studies of the nucleus of Edinger-Westphal and the oculomotor system. Society for Neuroscience Abstracts 11, 1040.

Erichsen, J.T., Evinger, C. \& May, P.J. (1992). Toward a functional anatomy of the cat Edinger-Westphal nucleus. Society for Neuroscience Abstracts 18, 855 .

Erichsen, J.T., Sun, W. \& MAY, P.J. (1995). Comparative anatomy of primate Edinger-Westphal nucleus. Investigative Ophthalmology and Visual Science 36, S461.

Evinger, C. (1988). Extraocular motor nuclei: Location, morphology and afferents. In Neuroanatomy of the Oculomotor System, ed. BüTTNEREnNever, J.A., Reviews of Oculomotor Research, pp.81-117. Amsterdam: Elsevier.

Freddo, T.F., Bartels, S.P., Barsotti, M.F. \& Kamm, R.D. (1990). The source of proteins in the aqueous humor of the normal rabbit. Investigative Ophthalmology and Visual Science 31, 125-137.

FUJII, J.T. (1992). Repetitive firing properties in subpopulations of the chick Edinger-Westphal nucleus. Journal of Comparative Neurology 316, 279-286.

Gamlin, P.D.R., Reiner, A., Erichsen, J.T., Karten, H.J. \& Cohen, D.H. (1984). The neural substrate for the pupillary light reflex in the pigeon. Journal of Comparative Neurology 226, 523-543.

Gamlin, P.D.R. \& Reiner, A. (1991). The Edinger-Westphal nucleus: Sources of input influencing accommodation, pupilloconstriction, and choroidal blood flow. Journal of Comparative Neurology 306, 425-438.

Gamlin, P.D.R., Zhang, Y., Clendaniel, R.A. \& Mays, L.E. (1994). Behavior of identified Edinger-Westphal neurons during ocular accommodation. Journal of Neurophysiology 72, 2368-2382.

GIVner, I. (1939). Episcleral ganglion cells. Archives of Ophthalmology 22, 82-88.

Hare, W.K., Magoun, H.W. \& Ranson, S.W. (1935). Pathways for pupillary constriction. Location of synapses in the path for the pupillary light reflex and of constrictor fibers of cortical origin. Archives of Neurology and Psychiatry 34, 1188-1194.

Henning, J. \& Himstedt, W. (1994). The pathway controlling the pupillary light reflex in urodeles. Experimental Brain Research 98, 412-420.

Hultborn, H., Mori, K. \& Tsukahara, N. (1978). The neuronal pathway subserving the pupillary light reflex. Brain Research 159, 255-267.
Innis, R.B. \& AghaJanian, G.K. (1986). Cholecystokinin-containing and nociceptive neurons in rat Edinger-westphal nucleus. Brain Research 363, 230-238.

Inomata, H., Bill, A. \& Smelser, G.K. (1972). Unconventional routes of aqueous humour outflow in cynomologous monkey (Macaca iris). American Journal of Ophthalmology 73, 893-907.

Iтон, K. (1977). Efferent projections of the pretectum in the cat. Experimental Brain Research 30, 89-105.

JAEGER, R.J. \& BENEVEnTo, L.A. (1980). A horseradish peroxidase study of the innervation of the internal structures of the eye. Evidence for a direct pathway. Investigative Ophthalmology and Visual Science 19, 575-583.

JAMPEL, R.S. \& MindeL, J. (1967). The nucleus for accommodation in the midbrain of the macaque. Investigative Ophthalmology 6, 40-50.

Johnson, D.A. \& Purves, D. (1981). Post-natal reduction of neural unit size in the rabbit ciliary ganglion. Journal of Physiology 318, 143-159.

Johnson, D.A. \& Purves, D. (1983). Tonic and reflex synaptic activity recorded in ciliary ganglion cells of anaesthetized rabbits. Journal of Physiology 339, 599-613.

Judge, S.J \& Cumming, B.G. (1986). Neurons in the monkey midbrain with activity related to vergence eye movement and accommodation. Journal of Neurophysiology 55, 915-930.

Kardon, R.H. \& Weingeist, T.A. (1998). Anatomy of the ciliary body and outflow pathways. In Glaucoma, ed. CAPrIOLI, J., Duane's Clinical Ophthalmology, pp. 1-26. Philadelphia, Pennsylvania: Lippincott Williams \& Wilkins.

Klooster, J., Vrensen, G.F.J.M., Müller, L.J. \& VAn der Want, J.J.L. (1995). Efferent projections of the olivary pretectal nucleus in the albino rat subserving the pupillary light reflex and related reflexes. A light microscopic tracing study. Brain Research 688, 34-46.

Kuchirwa, S., Kuchirwa, T. \& Suzuki, T. (1989). Comparative anatomy of the accessory ciliary ganglion in mammals. Anatomy and Embryology 180, 199-205.

Kuchirwa, S., Kuchirwa, T. \& NaKagawa, S. (1994). Localization of preganglionic neurons of the accessory ciliary ganglion in the midbrain: HRP and WGA-HRP studies in the cat. Journal of Comparative Neurology 340, 577-591.

Loewy, A.D., SAPer, C.B. \& Yamodis, D. (1978). Re-evaluation of the efferent projections of the Edinger-Westphal nucleus in the cat. Brain Research 141, 153-159.

Maciewicz, R., Phipps, B.S., Foote, W.E., Aronin, N. \& DiFiglia, M. (1983). The distribution of substance P-containing neurons in the cat Edinger-Westphal nucleus: Relationship to efferent projection systems. Brain Research 270, 217-230.

Maciewicz, R., Phipps, B.S., Grenier, J. \& Poletti, C.E. (1984). EdingerWestphal nucleus: Cholecystokinin immunocytochemistry and projections to spinal cord and trigeminal nucleus in the cat. Brain Research 299, 139-145.

May, P.J., Baker, H., Vidal, P.-P., Spencer, R.F \& Baker, R. (1987). Morphology and distribution of serotoninergic and oculomotor internuclear neurons in the cat midbrain. Journal of Comparitive Neurology 266, 150-170.

MAY, P.J. \& PORTER, J.D. (1998). The distribution of primary afferent terminals from the eyelids of macaque monkeys. Experimental Brain Research 123, 368-381.

May, P.J., Porter, J.D. \& Gamlin, P.D.R. (1992). Interconnections between the primate cerebellum and midbrain near-response regions. Journal of Comparative Neurology 315, 98-116.

MAY, P.J. \& WARREN, S. (1993). Ultrastructure of the macaque ciliary ganglion. Journal of Neurocytology 22, 1073-1095.

MAYS, L.E. \& PorTer, J.D. (1984). Neural control of vergence eye movements: Activity of abducens and oculomotor neurons. Journal of Neurophysiology 52, 743-761.

Mays, L.E., Porter, J.D., Gamlin, P.D.R. \& Tello, C.A. (1986). Neuronal control of vergence eye movements: Neurons encoding vergence velocity. Journal of Neurophysiology 56, 1007-1021.

Millar, J.C., Gabalt, B.T. \& Kaufman, P.L. (1998). Aqueous humour dynamics. In Glaucoma, ed. CAPrIOLI, J., Duane's Clinical Ophthalmology, pp. 1-45. Philadelphia, Pennsylvania: Lippincott Williams \& Wilkins.

Olucha, F., Martinez-Garcia, F. \& Lopez-Garcia, C. (1985). A new stabilizing agent for the tetramethyl benzidine (TMB) reaction product in the histochemical detection of horseradish peroxidase. Journal of Neuroscience Methods 13, 131-138. 
Parelman, J.J., Fay, M.T. \& Burde, R.M. (1984). Confirmatory evidence for a direct parasympathetic pathway to the internal eye structures. Transcripts of the American Ophthalmological Society 82, 371-380.

Pierson, R.J. \& CARpenter, M.B. (1974). Anatomical analysis of the pupillary light reflex pathways in the rhesus monkey. Journal of Comparative Neurology 158, 121-144.

Purves, D. (1983). Modulation of neuronal competition by postsynaptic geometry in autonomic ganglia. Trends in Neuroscience 6, 10-16.

Ranson, S.W. \& Magoun, H.W. (1933). The central pathway of the pupilloconstrictor reflex in response to light. Archives of Neurology and Psychiatry 30, 1193-1204.

Reiner, A., Karten, H.J., Gamlin, P.D.R. \& Erichsen, J.T. (1983). Parasympathetic ocular control. Functional subdivisions and circuitry of the avian nucleus of Edinger-Westphal. Trends in Neuroscience $\mathbf{6}$, $140-145$.

Reiner, A., Erichsen, J.T., Cabot, J.B., Evinger, C., Fitzgerald, M.E.C. \& KARTEN, H.J. (1991). Neurotransmitter organization of the nucleus of Edinger-Westphal and its projection to the avian ciliary ganglion. Visual Neuroscience 6, 451-472.

Røste, G.K. \& Dietrichs, E. (1988). Cerebellar cortical and nuclear afferents from the Edinger-Westphal nucleus in the cat. Anatomy and Embryology 178, 59-65.

Ruskell, G.L. \& Griffiths, T. (1979). Peripheral nerve pathway to the ciliary muscle. Experimental Eye Research 28, 277-284.

Sekiya, H., Kawamura, K. \& Ishikawa, S. (1984). Projections from the Edinger-Westphal complex of monkeys as studied by means of retrograde axonal transport of horseradish peroxidase. Archives Italiennes De Biologie 122, 311-319.

Sillito, A.M. \& ZBrozyna, A.W. (1970a). The activity characteristics of the preganglionic pupilloconstrictor neurons. Journal of Physiology 211, 767-779.

Sillito, A.M. \& ZBrozyna, A.W. (1970b). The localization of pupillo- constrictor function within the midbrain of the cat. Journal of Physiology 211, 461-477.

Somiya, H., Yosнimoto, M. \& Iто, H. (1992). Cytoarchitecture and fibre connections of the Edinger-Westphal nucleus in the filefish. Philosophical Transactions of the Royal Society B (London) 337, 73-81.

Sugimoto, T., Iтон, K. \& Mizuno, N. (1977). Localization of neurons giving rise to the oculomotor parasympathetic outflow: A HRP study in cat. Neuroscience Letters 7, 301-305.

Sugimoto, T., Itoh, K. \& Mizuno, N. (1978). Direct projections from the Edinger-Westphal nucleus to the cerebellum and spinal cord in the cat: An HRP study. Neuroscience Letters 9, 17-22.

Sun,W. (1995). Neuronal components of the pupillary light reflex pathways in the cat. Dissertation. University of Mississippi Medical Center.

Sun, W., ERICHSEN, J.T. \& MAY, P.J. (1994). NADPH-diaphorase reactivity in ciliary ganglion neurons: A comparison of distributions in the pigeon, cat, and monkey. Visual Neuroscience 11, 1027-1031.

Sun, W. \& May, P.J. (1993). Organization of the extraocular and preganglionic motoneurons supplying the orbit in the lesser galago. Anatomical Record 237, 89-103.

Sun, W. \& MAY, P.J. (1995). Morphology and connections of the pupillary light reflex pathway in cat and monkey. Investigative Ophthalmology and Visual Science 36, S12.

Toyoshima, K., Kawana, E. \& SaKai, H. (1980). On the neuronal origin of the afferents to the ciliary ganglion in cat. Brain Research $\mathbf{1 8 5}$, 67-76.

VANN, V.R. \& Atherton, S.S. (1991). Neural spread of herpes simplex virus after anterior chamber inoculation. Investigative Ophthalmology and Visual Science 32, 2462-2472.

WARWICK, R. (1954). The ocular parasympathetic nerve supply and its mesencephalic sources. Journal of Anatomy 88, 71-93.

Westheimer, G. \& Blair, S.M. (1973). The parasympathetic pathways to internal eye muscles. Investigative Ophthalmology 12, 193-197. 